\title{
Evaluation of Elbow Stretch Reflex Using a Portable Hand-driven Isokinetic System in Normal Adults
}

\author{
Jeong-Hwan Seo, M.D., Soon-Won Yook, M.D., Chul-Gyu Song, Ph.D. ', \\ Myoung-Hwan Ko, M.D., Sung-Hee Park, M.D.
}

\begin{abstract}
Department of Physical Medicine and Rehabilitation, Institute for Medical Sciences, Chonbuk National University Medical School, Research Institute of Clinical Medicine, Chonbuk National University Hospital, ${ }^{1}$ Division of Electronics and Information Engineering, Chonbuk National University, Jeonju 561-180, Korea
\end{abstract}

Objective To evaluate normal healthy persons without spasticity to observe normal findings of the elbow stretch reflex using a newly developed, portable, hand-driven spasticity-measuring system.

Method Thirty normal persons without any disease involving the central or peripheral nervous system were enrolled in this study. The portable hand-driven isokinetic system is able to measure the joint angle, angular velocity, electromyographic (EMG) signals, and torque during elbow passive extension-flexion. One set of 10 passive elbow extension and flexion movements was performed for data acquisition at each angular velocity, including 60, 90, 120, 150 and 180 degrees per second $(\% / \mathrm{sec})$. Electromyographic data were collected from the biceps brachii and the triceps brachii. Torque data were collected from sensors around the wrist.

Results We were able to detect EMG activity and torque in all subjects by using the new portable hand-driven isokinetic system. EMG activity and torque increased with incremental increase of angular velocities. The joint angle of maximal EMG activity according to different angular velocities did not show any significant difference $\left(116^{\circ}-127^{\circ}\right.$ in elbow extension and $37^{\circ}-66^{\circ}$ in elbow flexion). The joint angles of maximal torque according to different angular velocities were not significantly different either.

Conclusion Using the portable hand-driven isokinetic system on the elbows of normal subjects, we were able to obtain expected results. By considering our normal findings of the elbow stretch reflex using this system, we propose that the various aspects of spasticity-related data can be measured successfully.

Key Words Isokinetic exercise, Portable system, Stretch reflex

Received November 23, 2010; Accepted June 1, 2011

Corresponding author: Soon-Won Yook

Department of Physical Medicine and Rehabilitation, Chonbuk National University Medical School, San 2-20, Keumam-dong, Dukjin-gu, Jeonju 561-180, Korea

Tel: +82-63-250-1810, Fax: +82-63-254-4145, E-mail: credomea@naver. com

(c) This is an open-access article distributed under the terms of the Creative Commons Attribution Non-Commercial License (http://creativecommons.org/ licenses/by-nc/3.0) which permits unrestricted noncommercial use, distribution, and reproduction in any medium, provided the original work is properly cited. Copyright $\odot 2011$ by Korean Academy of Rehabilitation Medicine

\section{INTRODUCTION}

In the clinical field, spasticity is commonly assessed by the modified Ashworth scale (MAS). ${ }^{1}$ Even though the inter-rater and intra-rater reliability of the MAS is good, some limitations exist because spasticity is measured subjectively by the rater's own hand. ${ }^{2,3}$

The pendulum test is a biomechanical method of evalu- 
ating muscle tone by using gravity to provoke muscle stretch reflex during passive swinging of the lower limb. Some researchers have reported that the ratio of the amplitude of the swings significantly correlated with clinical scales such as the MAS scores in spastic patients. However, this test also has limitations, such as difficulty in keeping patients in a fully relaxed status, difficulty in measuring the spasticity in different angular velocities and in usage at other joints. ${ }^{4}$

The isokinetic dynamometer has been widely used for quantitative assessment and evaluation of spasticity. It allows accurate joint stretching according to specific angular velocities and quantitative measurement of resistance and spasticity. However, it is hardly used in clinical settings because of the large size of the device as well as poor mobility. ${ }^{5}$

In addition, the H-reflex and T-reflex are available for assessing spasticity. However, the results of these tests poorly correlate with the cause of spasticity, lesion site and degree of spasticity. ${ }^{6}$

To overcome the problems that were encountered using the previous methods of measuring spasticity, we introduced a portable hand-driven isokinetic system for measuring spasticity quantitatively and comprehensively with mobility. ${ }^{7}$ Upon evaluation of spasticity of the elbow using this system, the examiner grasps the wrist of the subject and passively extends and flexes the elbow joint as the clinical bedside method for measuring spasticity. This system is designed to measure the joint angle, EMG signals, angular velocity, and torque during passive elbow movements.

The objective of this study was to evaluate the stretch reflex of the elbow joint of normal persons and analyze the parameters before the application of this system on patients with spasticity.

\section{MATERIALS AND METHODS}

\section{Participants}

Thirty normal persons (18 males and 12 females) without history of diseases involving the central nervous system (mean age 25.7, range 22-30 years) were enrolled in this study. The subjects did not show neurologic symptoms, signs or spasticity either (MAS 0).

\section{Methods}

Portable isokinetic system: This developed system was designed to measure the angle, angular velocity, torque and EMG signals by moving the elbow joint of a subject with the examiner's own hand. The surface EMG signal was measured using $10 \mathrm{~mm}$ diameter, disposable Ag-AgCl electrodes (Meditrace ${ }^{\mathrm{TM}}$ 200, Tyco Healthcare Group LP, Mansfield, Massachusetts, USA). Two active electrodes were placed on the belly of the biceps brachii (BB) muscle and triceps brachii muscle, respectively. Two reference electrodes were attached firmly on the medial and lateral aspect of the elbow joint. The ground electrode was placed on the middle of the forearm. The joint angle of the elbow was measured by means of a twin-axis flexible electro-goniometer $\left(\mathrm{SG}_{150}{ }^{\circledR}\right.$, Biometrics Ltd., Gwent, UK) attached on the arm and forearm along the lateral side. In addition, the angular velocity was calculated by the differentiation of the angle signals. Torque was measured by two pressure sensors (FlexiForce A201 ${ }^{\circledR}$ Tekscan, South Boston, Massachusetts, USA) attached around the wrist. The examiner grabbed the wrist and the pressure sensors and performed passive elbow extension/flexion movement during this study. The resulting data were then transferred to a laptop computer via its USB port and simultaneously displayed on the monitor. The data were also analyzed by newly developed software using the Labview language (ver. 8.6,

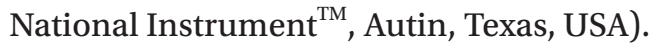

Experimental protocol: The subjects comfortably lay down in the supine position, and the upper limb

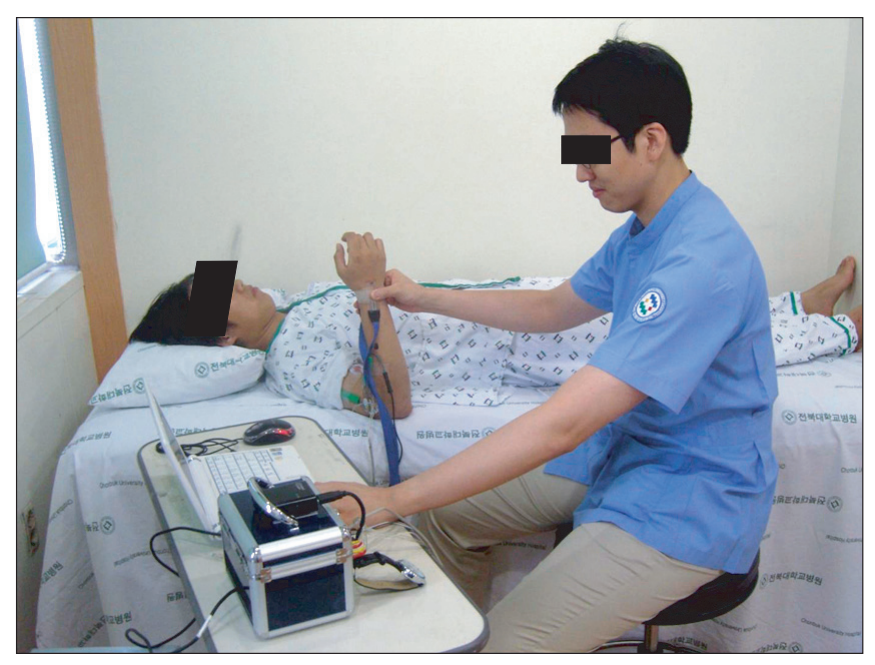

Fig. 1. Evaluation of normal elbow movement using a portable hand-driven isokinetic system. 
was slightly abducted and relaxed (Fig. 1). To monitor the activity of the elbow flexor and extensor, surface electrodes (Meditrace 200, Kendall, US) were attached to the arm. The skin for the electrodes was cleaned with a 95\% ethanol mixture to reduce skin impedance. Two pressure sensors were also attached on the wrist of the subject, anteriorly and posteriorly. The 'sensor calibration' button was used to manually remove the offset of the signals measured by the various sensors. The ' 0 ' setting' and ' $90^{\circ}$ setting' buttons were used for converting the voltage signals obtained from the flexible electro-goniometer to the specific angular displacement. In order to reduce the muscle tension, the subjects were taught not to contract the biceps and triceps muscles during the test and had 3 instances of passive extensionflexion practice before the test. The subjects lay on a bed in a relaxed position. The starting position involved the slight abduction of the shoulder, neutral position of the wrist and full flexion of the elbow. In order to reduce muscle tension, the subjects maintained this starting position for at least 2 minutes. The tests started after confirming the silence of EMG signals by monitoring them. The subject's elbow joint was passively extended and flexed by the examiner at a randomly selected stretching angular velocity of either 60, 90, 120, 150 and $180^{\circ} / \mathrm{sec}$, in order to avoid adaptation of the stretch response. A motion from full flexion to full extension was defined as 'elbow extension', whereas 'elbow flexion' was defined as a motion from full extension to full flexion. 'Full extension' meant an angle of $0^{\circ}$ between the arm and forearm, while 'full flexion' meant an angle of about $120^{\circ}$. One cycle of elbow joint motion consisted of one elbow extension and one flexion over an approximate angle range of $120^{\circ} \rightarrow 0^{\circ} \rightarrow 120^{\circ}$. Measurements were performed repeatedly ten times at the selected stretching angular velocity with at least 10 seconds of rest between each measurement. Proper angular velocity of the elbow joint motion could be maintained by the beeping sound of the device. The maximal EMG amplitude and the maximal torque were collected at each stretching angular velocity.

\section{Statistics}

Statistical analysis was conducted using SPSS ver. 13.0 software. The 2-samples t-test was used to compare changes in maximal amplitude and torque with each stretching angular velocity. The level of statistical significance was set at a p-value less than 0.05 .

\section{RESULTS}

We observed EMG activity and torque even in normal persons without spasticity (Fig. 2). EMG activity was observed in biceps when the elbow was extended and in triceps when the elbow was flexed. Torque was measured when the elbow was extended and flexed.

\section{The maximal EMG activity}

In normal subjects without spasticity, the maximal EMG activities recorded on biceps and triceps showed an increasing tendency with incremental increase of stretching angular velocities (Table 1). The maximal EMG

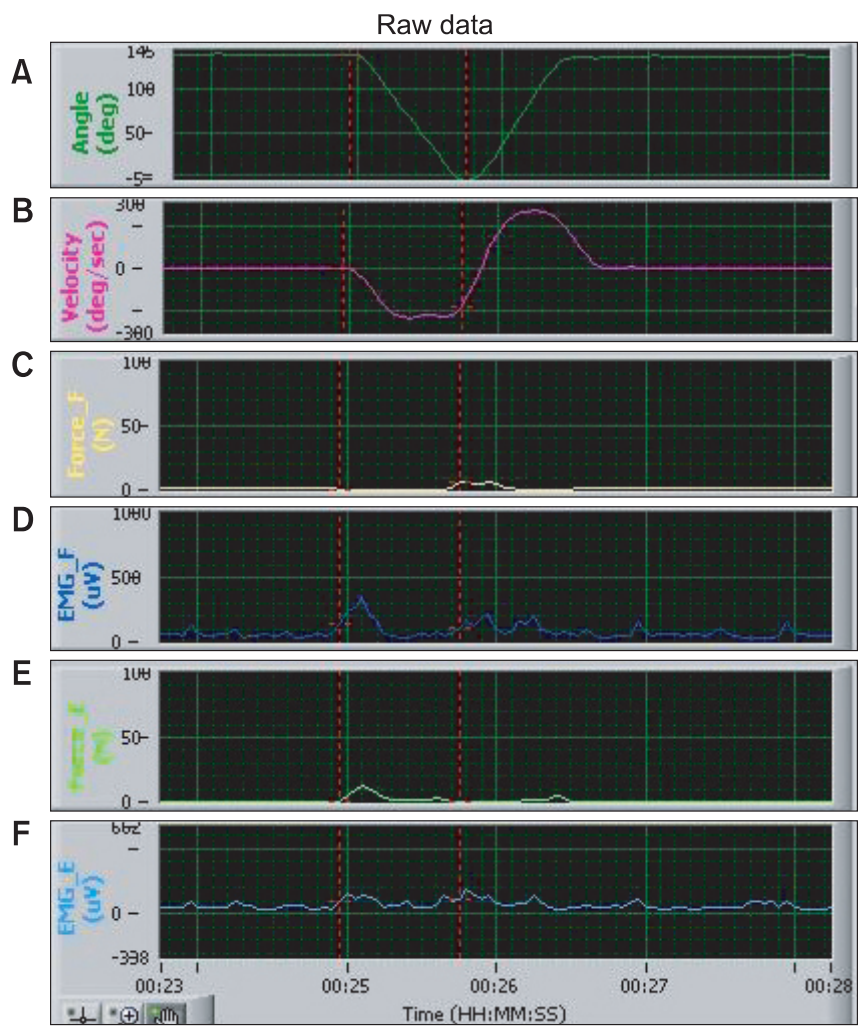

Fig. 2. Isokinetic exercise analysis tool. EMG activity and torque were detected on elbow extension and flexion in normal subject. (A) The elbow joint angle checked by electrogoniometer, (B) the angular velocity calculated by the device, (C) flexion torque checked on sensors located on the wrist, (D) the EMG signal detected in biceps muscle, (E) torque checked on sensors located on the wristed in triceps muscle, (F) the EMG signal detected in triceps muscle. 
Table 1. Maximal Electromyographic (EMG) Activity on Elbow Movement According to Angular Velocity in Normal Subjects

\begin{tabular}{ccc}
\hline $\begin{array}{c}\text { Angular velocity } \\
(\boldsymbol{\circ} / \mathrm{sec})\end{array}$ & \multicolumn{2}{c}{ EMG $(\mu \mathrm{V})$} \\
\cline { 2 - 3 } & Extension & Flexion \\
\hline 60 & $103.33 \pm 19.20$ & $117.40 \pm 32.01$ \\
90 & $131.87 \pm 34.50$ & $121.07 \pm 21.86$ \\
120 & $137.87 \pm 33.55^{*}$ & $160.30 \pm 46.54^{*}$ \\
150 & $151.33 \pm 34.48$ & $223.33 \pm 67.31^{*}$ \\
180 & $175.60 \pm 59.83$ & $232.97 \pm 63.14$ \\
\hline
\end{tabular}

Values are mean \pm standard deviation

${ }^{*} \mathrm{p}<0.05$, comparison with the values of the previous (30 degrees/sec less) angular velocity

Table 2. Maximal Torque on Elbow Movement According to Angular Velocity in Normal Subjects

\begin{tabular}{clc}
\hline $\begin{array}{c}\text { Angular velocity } \\
(\% / \text { sec })\end{array}$ & \multicolumn{2}{c}{ Torque $(\mathrm{Nm})$} \\
\cline { 2 - 3 } & Extension & Flexion \\
\hline 60 & $3.70 \pm 1.21$ & $4.03 \pm 1.59$ \\
90 & $4.57 \pm 1.38^{*}$ & $7.37 \pm 2.48^{*}$ \\
120 & $5.87 \pm 1.61$ & $9.23 \pm 3.67$ \\
150 & $6.77 \pm 2.64$ & $10.53 \pm 3.59^{*}$ \\
180 & $8.20 \pm 3.11^{*}$ & $15.93 \pm 3.90$ \\
\hline
\end{tabular}

Values are mean \pm standard deviation

${ }^{*} \mathrm{p}<0.05$, comparison with the values of the previous (30 degrees/sec less) angular velocity

activity recorded on the biceps when the elbow joint was passively extended showed increasing tendency compared to the stretching angular velocity of $60^{\circ} / \mathrm{sec}$ and $90^{\circ} / \mathrm{sec}, 90^{\circ} / \mathrm{sec}$ and $120^{\circ} / \mathrm{sec}, 120^{\circ} / \mathrm{sec}$ and $150^{\circ} / \mathrm{sec}$, $150^{\circ} / \mathrm{sec}$ and $180^{\circ} / \mathrm{sec}$, respectively. The maximal EMG activity recorded on the biceps significantly increased on the stretching angular velocity of $120^{\circ} / \mathrm{sec}$ compared to the stretching angular velocity of $90^{\circ} / \mathrm{sec}$. The maximal EMG activity recorded on the triceps when the elbow joint was passively flexed increased on the stretching angular velocity of $120^{\circ} / \mathrm{sec}$ and $150^{\circ} / \mathrm{sec}$ compared to the stretching angular velocity of $90^{\circ} / \mathrm{sec}$ and $120^{\circ} / \mathrm{sec}$, respectively $(\mathrm{p}<0.05)$.

\section{The maximal torque of the elbow joint}

In normal subjects without spasticity, the maximal torque recorded on the sensors attached to the subject's wrist increased with incremental increase of stretching angular velocities (Table 2). When the elbow joint was
Table 3. Joint Angle of Maximal EMG Activity According to Angular Velocity in Normal Subjects

\begin{tabular}{ccc}
\hline $\begin{array}{c}\text { Angular velocity } \\
(\% / \text { sec })\end{array}$ & \multicolumn{2}{c}{ Angle $\left({ }^{\circ}\right)$} \\
\cline { 2 - 3 } & Extension & Flexion \\
\hline 60 & $116.07 \pm 23.75$ & $37.33 \pm 21.15$ \\
90 & $124.78 \pm 23.91$ & $48.40 \pm 25.43$ \\
120 & $127.15 \pm 7.19$ & $49.91 \pm 24.30$ \\
150 & $124.19 \pm 8.61$ & $66.88 \pm 28.15$ \\
180 & $121.63 \pm 8.21$ & $58.60 \pm 38.27$ \\
\hline
\end{tabular}

Values are mean \pm standard deviation

Table 4. Joint Angle of Maximal Torque on Elbow Movement According to Angular Velocity in Normal Subjects

\begin{tabular}{ccc}
\hline $\begin{array}{c}\text { Angular velocity } \\
(\% / \text { sec })\end{array}$ & \multicolumn{2}{c}{ Angle $\left({ }^{\circ}\right)$} \\
\cline { 2 - 3 } & Extension & Flexion \\
\hline 60 & $117.47 \pm 21.52$ & $48.79 \pm 35.12$ \\
90 & $114.78 \pm 28.67$ & $31.60 \pm 13.14$ \\
120 & $120.68 \pm 7.61$ & $20.75 \pm 5.19$ \\
150 & $117.38 \pm 5.92$ & $26.13 \pm 8.61$ \\
180 & $113.48 \pm 6.85$ & $27.72 \pm 7.36$ \\
\hline
\end{tabular}

Values are mean \pm standard deviation

passively extended, the maximal extension torque recorded on the wrist increased on stretching angular velocity of $90^{\circ} / \mathrm{sec}$ and $180^{\circ} / \mathrm{sec}$ compared to $60^{\circ} / \mathrm{sec}$ and $150 \%$ sec, respectively. The maximal flexion torque recorded on the wrist when the elbow joint was passively flexed increased on stretching angular velocity of $90^{\circ} /$ sec and $150^{\circ} / \mathrm{sec}$ compared to $60^{\circ} / \mathrm{sec}$ and $150^{\circ} / \mathrm{sec}$, respectively $(\mathrm{p}<0.05)$. Interestingly, the maximal torque increased as they were compared to the stretching angular velocity of over $60^{\circ} / \mathrm{sec}$ difference $(\mathrm{p}<0.05)$.

Elbow joint angle when maximal EMG activity was recorded

In normal subjects without spasticity, the elbow joint angle at the maximal EMG activity on biceps was the biggest at the angular velocity of $120^{\circ} / \mathrm{sec}$. The elbow joint angle at the maximal EMG activity on biceps was significantly different between the stretching angular velocity of $60^{\circ} / \mathrm{sec}$ and $120^{\circ} / \mathrm{sec}$, and $120^{\circ} / \mathrm{sec}$ and $180^{\circ} /$ sec, respectively. In normal subjects without spasticity, the elbow joint angle when the maximal EMG activity on triceps was observed was the biggest with stretching angular velocity of $150^{\circ} / \mathrm{sec}$. However, there was no 
significant difference between the stretching angular velocities (Table 3 ).

The elbow joint angle when the maximal torque was recorded

In normal subjects without spasticity, the elbow joint angle when the maximal torque was observed on passive extension was the biggest at the angular velocity of $120^{\circ} /$ sec. The elbow joint angle when the maximal torque of the elbow joint was observed on passive flexion was the biggest at the angular velocity of $60^{\circ} / \mathrm{sec}$ (Table 4 ).

\section{DISCUSSION}

The present study showed that EMG activity and torque during the passive motion of elbow joint increased with incremental increase of stretching angular velocities. These results are possibly due to 1) the increase of inertial force due to acceleration, 2) viscoelastic property of muscle and joint tissue, and 3) antagonistic muscle contraction due to stretch reflex. ${ }^{8-10}$

Simon et al. ${ }^{11}$ reported that EMG activity and torque of the knee joint increased with incremental increase of angular velocities during the knee joint's passive extension-flexion in rat. These findings were possibly because of passive torque and stretch reflex related to the proprioceptor. Pisano et al. ${ }^{12}$ reported that the EMG activity and torque of flexor carpi radialis and extensor digitorum communis were recorded when a normal subject's wrist stretched with a servo-controlled torque motor in $500^{\circ} / \mathrm{sec}$ of angular velocity increased compared to $10^{\circ} / \mathrm{sec}$ of angular velocity. They also reported that stretch reflex was recorded in $54 \%$ of normal subjects. Lee et al. ${ }^{13}$ reported that stretch reflex was recorded in the ankle joints of all normal subjects and hemiplegic patients examined with an isokinetic dynamometer and dynamic EMG recorder. In the present study, the stretch reflex was recorded in all subjects. The maximal torque recorded on the wrist during passive motion increased as the stretching angular velocity significantly increased over $60^{\circ} / \mathrm{sec}$ interval. Direct comparison with other studies is inappropriate because previous studies involving the elbow joint are lacking. In the present study, all normal subjects showed stretch reflex, which was different to the results of Pisano's study. ${ }^{12}$ Those differences are thought to be caused by 1) the differences of spasticity measurement sites, 2) the differences of length of each muscle, and 3) the differences of measurement technique. Clinical experiences that the spasticity was observed more commonly in the elbow than in the wrist support our results.

In clinical settings, the examiner usually passively extends and flexes the upper limb for measuring the spasticity of the upper extremity. Quantitative data such as the joint angle, torque and EMG activity was obtained during the passive elbow extension-flexion. ${ }^{14,15}$ On examining the spasticity with the modified Ashworth scale, the data tended to be subjective, and it was difficult to maintain the stretch angular velocity. Therefore, we designed this portable hand-driven isokinetic system to make an electric "beep" sound to match extensionflexion to maintain the stretch angular velocity. Before the measurement, the examiner practiced the rhythmic stretch sufficiently. In normal subjects, the elbow joint angle, when the maximal EMG activity was observed in each stretch angular velocity, was 116-127 degrees on elbow extension, 37-66 degrees on elbow flexion. The difference of the angle when the maximal EMG activity was observed was not significant between each stretching angular velocity (Table 3 ). That is, the joint angle when the maximal stretch reflex appears was similar in each stretch angular velocity. Lee et al. ${ }^{16}$ also observed the maximal torque of the ankle when passive joint exercise was applied with isokinetic dynamometer. They presented that the joint angle of maximal torque was not different between each stretch angular velocity.

Levin and Feldman ${ }^{17}$ quantitatively measured the stretch reflex by tonic stretch reflex threshold (TSRT), which is a linear regression of dynamic stretch reflex threshold. Our results suggested a way to analyze the stretch reflex quantitatively using comprehensive data such as EMG activity, joint angle and angular velocity, and torque.

The objective of this study was to evaluate the elbow joint of normal persons and analyze the parameters before the application of the new portable hand-driven isokinetic exercise system on spastic patients. We could detect EMG activity and torque by the system in normal subjects without spasticity. The data we collected could be good reference data for analyzing spasticity with this system.

The limitation of this study was that the baseline of the EMG signal was not calm. The authors had difficulties 
in detecting the take off point of EMG signal from the baseline. This was the reason why we used the maximal EMG activity and torque. To overcome this problem, the authors are currently trying to improve the system.

\section{CONCLUSION}

The portable hand-driven isokinetic system was designed to analyze spasticity both quantitatively and comprehensively. Using this system, we were able to detect EMG activity and torque in normal subjects without spasticity. The results were relatively smaller than that of patients with spasticity. This suggests that the portable hand-driven isokinetic system is precise enough to detect this type of delicate data. Those results are considered to be caused from the stretch reflex and viscoelastic component of muscle and joint. They could be reference data for analyzing the spasticity in the future.

\section{ACKNOWLEDGEMENTS}

This work was supported by the National Research Foundation of Korea funded by the Korean Government (No. 2010-0027510).

\section{REFERENCES}

1. Ashworth B. Preliminary trial of carisprodol in multiple sclerosis. Practitioner 1964; 192: 540-542

2. Gregson JM, Leathley M, Moore AP, Sharma AK, Smith TL, Watkins CL. Reliability of the Tone Assessment Scale and the modified Ashworth scale as clinical tools for assessing poststroke spasticity. Arch Phys Med Rehabil 1999; 80: 1013-1016

3. Gregson JM, Leathley MJ, Moore AP, Smith TL, Sharma AK, Watkins CL. Reliability of measurements of muscle tone and muscle power in stroke patients. Age Ageing 2000; 29: 223-228

4. Fowler EG, Nzigwe AI, Ho TW. Sensitivity of the pendulum test for assessing spasticity in persons with cerebral palsy. Dev Med Child Neurol 2000; 42: 182189

5. Alibiglou L, Rymer WZ, Harvey RL, Mirbagheri MM. The relation between Ashworth scores and neuro- mechanical measurements of spasticity following stroke. J NeuroEng Rehabil 2008; 5: 18-31

6. Kohan AH, Abootalebi S, Khoshnevisan A, Rahgozar M. Comparison of modified Ashworth scale and Hoffmann reflex in study of spasticity. Acta Med Iran 2010; 48: 154-157

7. Seo JH, Han SH, Kim KS, Song CG, Ko MH, Park $\mathrm{SH}$. Evaluation of stretch reflex threshold on stroke patients using the new portable spasticity-measuring system. J Korean EMG Electrodiagn Med 2009; 11: 8591

8. Sinkjaer T, Toft E, Andreassen S, Hornemann BC. Muscle stiffness in human ankle dorsiflexors: intrinsic and reflex components. J Neurophysiol 1988; 60: 11101121

9. Bucho I, Anastasievich R. Activity of fusimotor neurons during reflex muscle contraction. Neirofiziologiia 1984; 16: 630-637

10. Nichols TR, Houk JC. Improvement in linearity and regulation of stiffness that results from actions of stretch reflex. J Neurophysiol 1976; 39: 119-142

11. Simon BN, Verstraete MC, Reisberg S, Mulavara AP. Torque production vs muscle activity during knee flexion extension. Engineer Med Biol Mag 1994; 1: 382-383

12. Pisano F, Miscio G, Colombo R, Pinelli P. Quantitative evaluation of normal muscle tone. J Neurol Sci 1996; 135: 168-172

13. Lee SJ, Kwon BS, Chung SY. The significance of stretch reflex threshold speed in quantitative assessment of spasticity. J Korean Acad Rehab Med 2000; 24: 208-214 14. Neilson PD, McCaughey J. Effect of contraction level and magnitude of stretch on tonic stretch reflex transmission characteristics. J Neurol Neurosurg Psychiatry 1981; 44: 1007-1012

15. Pandyan AD, Price CI, Rodgers H, Barnes MP, Johnson GR. Biomechanical examination of a commonly used measure of spasticity. Clin Biomech 2001; 16: 859-865

16. Lee SJ, Kwon BS, Park ST. The assessment of spasticity using isokinetic eccentric torque measurement. J Korean Acad Rehab Med 1999; 23: 828-834

17. Levin MF, Feldman AG. The role of stretch reflex threshold regulation in normal and impaired motor control. Brain Res 1994; 657: 23-30 